\title{
AS PRÁTICAS EQUESTRES E O LAZER DOS PORTO-ALEGRENSES (DÉCADAS DE 1920 A 1940)
}

Recebido em: 18/10/2013

Aceito em: 03/05/2014

\author{
Ester Liberato Pereira ${ }^{1}$ \\ Universidade Federal do Rio Grande do Sul \\ Porto Alegre - RS - Brasil \\ Janice Zarpellon Mazo ${ }^{2}$ \\ Universidade Federal do Rio Grande do Sul \\ Porto Alegre - RS - Brasil
}

\begin{abstract}
RESUMO: No Rio Grande do Sul, a parceria entre homem e cavalo esteve presente nos momentos de lazer. Embora as práticas equestres desenvolvessem, ao longo dos anos, propriedades características de um esporte moderno, também estavam aliadas ao lazer. Este estudo objetiva compreender como se sucederam as manifestações de lazer dos porto-alegrenses nas práticas equestres, nas décadas de 1920 a 1940 . Utilizaram-se as seguintes fontes de pesquisa: atas de entidades equestres, Revista do Globo e jornais Semanário Turfista, Diário de Notícias, Equi, Canter e Gazeta de Porto Alegre. Os militares, pioneiros na prática do hipismo em Porto Alegre, tendiam a um fim mais utilitário das práticas equestres; mas também, esporadicamente, praticavam como lazer. Muitos civis começaram a praticar o hipismo no tempo destinado ao lazer e, posteriormente, ingressaram em competições hípicas.
\end{abstract}

PALAVRAS CHAVE: Atividades de Lazer. Esportes. História.

\section{EQUESTRIAN PRACTICES AND THE LEISURE IN PORTO ALEGRE (DECADES 1920-1940)}

ABSTRACT: In Rio Grande do Sul, the partnership between man and horse was present during leisure time. Although equestrian practices have developed, over the years, characteristic properties of a modern sport, they were also allied to leisure. This study aims to understand how leisure demonstrations of Porto Alegre people were ensued in the equestrian practices in the decades from 1920 to 1940, in Porto Alegre. The following sources were used: minutes of equestrian organizations, Globo magazine and Semanário Turfista, Diário de Notícias, Equi, Canter and Gazeta de Porto Alegre newspapers. The military pioneered in the practice of riding in Porto Alegre, tending to

\footnotetext{
${ }^{1}$ Doutoranda do Programa de Pós-Graduação em Ciências do Movimento Humano (PPGCMH) da Escola de Educação Física (ESEF) da Universidade Federal do Rio Grande do Sul (UFRGS). Bolsista da Coordenação de Aperfeiçoamento de Pessoal de Nível Superior (CAPES).

2 Professora dos cursos de Licenciatura e de Bacharelado em Educação Física e do PPGCMH da ESEF/UFRGS.
} 
a more utilitarian view of equestrian practices; but also sporadically practiced as leisure. Many civilians began practicing equestrianism in leisure time and later joined in equestrian competitions.

KEYWORDS: Leisure Activities. History. Sports.

\section{Introdução}

O presente estudo trata de práticas culturais que estão relacionadas com a configuração do cenário sociocultural de Porto Alegre, bem como, do estado do Rio Grande do Sul: as práticas equestres. Desde o século XVII, no estado do Rio Grande do Sul, já havia redutos de criação de cavalos nas denominadas reduções jesuíticas, onde os indígenas tiveram seu primeiro contato com estes animais, passando a utilizá-los, paulatinamente, como meio de transporte, tração, auxiliar da caça, de disputas por territórios e montaria (RUBERT, 1998).

O cavalo e o sul-rio-grandense sempre se associaram ao longo da história do Rio Grande do Sul, desde a sua formação enquanto um Estado, por meio de batalhas por conquistas de territórios, até as atividades de trabalho e transporte na vida campesina, como montaria e tração. Não seria surpreendente que tal parceria entre homem e animal estivesse presente, também, nos momentos de lazer e diversão. No estudo de Mazo (2003), foi evidenciado que, por volta da segunda metade do século XIX, uma das práticas de lazer de parcela da população eram as corridas de cavalos conhecidas por "carreiras em cancha reta". Tais disputas constituíam o passatempo preferido dos sulrio-grandenses campeiros.

Em meio à tradição sul-rio-grandense de uma elite rural na criação e aperfeiçoamento de raças de cavalos, aliada ao acompanhamento do processo de desenvolvimento da cidade, as primordiais carreiras de cancha reta favoreceram a fundação dos primeiros hipódromos (prados) de Porto Alegre, destinados à prática do 
turfe. A existência simultânea de quatro hipódromos possibilitou o desenvolvimento do turfe sul-rio-grandense, o qual passou a configurar-se como um dos principais espetáculos esportivos no início do século XX, em Porto Alegre. As práticas equestres faziam-se sentir significativamente, não somente no Rio Grande do Sul, como também em outros lugares, enquanto atividades de lazer e esporte, por meio dos chamados “jogos de cavalheiros”, já na segunda metade do século XIX, no Rio de Janeiro (DEL PRIORE, 2009).

Por sua vez, a equitação ${ }^{3}$, que começou a ser praticada no âmbito das instituições militares, por volta do início do século XIX, também englobava atividades de lazer, segundo Roessler e Rink (2006). Dentre as práticas da equitação, está o hipismo, cuja modalidade do salto constitui a mais divulgada conforme Vieira e Freitas (2007). A prática do salto do hipismo, em Porto Alegre, imprimiu seus primeiros passos oficiais, na região, por meio da denominada Escolta Presidencial, criada em 25 de janeiro de 1916, por meio do Decreto-Lei $\mathrm{n}^{\circ} 2.172$, a qual passava a constituir uma nova unidade da Brigada Militar - como é denominada a polícia militar do Rio Grande do Sul.

A Escolta Presidencial, constituindo uma unidade autônoma da corporação da Brigada Militar, tinha, por missão principal, exercer o serviço de guarda, vigilância e segurança do palácio do governo do Estado e realizar a segurança pessoal do Presidente da Província - atual governador do Estado. Esta Escolta, que contou, no princípio, com um efetivo de quase 90 homens, a fim de melhor preparar e condicionar seus cavalos e cavaleiros para exercer as funções, desenvolvia a prática do hipismo ( $4^{\circ}$ RPMON..., 2009).

\footnotetext{
${ }^{3}$ Neste estudo, compartilhamos do entendimento de "equitação" de Roessler e Rink (2006, p.1), os quais a definem como "atividades esportivas e de lazer desenvolvidas pelo conjunto ser humano/cavalo, sempre que o primeiro estiver sobre o dorso do segundo".
} 
A prática do salto do hipismo, posteriormente, expande-se também para a parcela civil da população, aproximando-se da igualdade de acesso proposta por Guttmann (1978) para compor um esporte moderno. Além de as fontes históricas não ocultarem que tal prática era somente acessível aos detentores de capital social e econômico, elas também realçavam e reforçavam tal distinção por meio do emprego de termos tais como, por exemplo, "elegante", "elite porto-alegrense", "figuras destacadas da sociedade gaúcha” (A FESTA..., 1929; FESTA..., 1943).

O exército, por sua vez, dentre seus eventos hípicos, realizava a Semana do Cavalo de Guerra. Esta era mais uma oportunidade de integração de autoridades políticas e militares, como prefeitos, generais e comandantes (A SEMANA..., 1932, p. 33). Também chamada de Campeonato Nacional Cavalo D’Armas ${ }^{4}$, a Semana do Cavalo de Guerra congregava competidores militares do exército e da Brigada Militar. Uma das provas realizadas neste campeonato era a steeple-chase - um tipo de corrida de cavalos com obstáculos a transpor, semelhante ao atual Concurso Completo de Equitação $(\mathrm{CCE})^{5}$-, tomando lugar no Hipódromo da Associação Protetora do Turfe (CAMPEONATO..., 1935).

Neste período, Porto Alegre era uma cidade que se contagiava pelos ares da modernidade, com padrões e valores de diversas metrópoles. Deste modo, as trajetórias dos produtos e símbolos da modernidade, das sociedades urbanas e industriais, se

\footnotetext{
${ }^{4}$ No Brasil, o Campeonato do Cavalo D'armas era realizado, frequentemente, antes da mecanização das unidades hipomóveis do exército brasileiro. De origem europeia, em suas primeiras versões, tinha, como meta, preparar os cavalos para combates. Por este motivo, o esporte era conhecido como cavalo d'armas. Os animais deveriam ser ágeis, rápidos, obedientes, resistentes e corajosos. Apesar da mecanização da cavalaria e da escassez das guerras, a prática continuou sendo desenvolvida, principalmente, na Europa, América do Norte, Austrália e Nova Zelândia (VIEIRA; FREITAS, 2007). Pelo fato de ser disputado apenas por militares, este gênero de competição passou a chamar-se military (MORGADO, 1990). A primeira competição internacional foi registrada em 1902 (VIEIRA; FREITAS, 2007).

${ }^{5} \mathrm{O}$ Concurso Completo de Equitação (CCE) figurou, pela primeira vez, no calendário dos Jogos Olímpicos, em 1912, em Estocolmo, na Suécia, como um campeonato militar, não admitindo, na competição, em um primeiro momento, cavaleiros civis nem amazonas (MORGADO, 1990).
} 
entrelaçam e se confundem. As práticas de lazer se alargam na mesma velocidade com que se desenvolvem bairros e cidades industriais, refletindo uma nova organização social do trabalho (STÉDILE, 2010).

Diante de tal panorama, este estudo objetiva compreender como se sucederam as manifestações de lazer nas práticas equestres, nas décadas de 1920 a 1940, em Porto Alegre.

\section{Metodologia}

O objetivo proposto foi contemplado por meio de uma coleta de informações em fontes, como atas de entidades equestres, a Revista do Globo e os jornais Diário de Notícias e Gazeta de Porto Alegre. Estes eram importantes jornais porto-alegrenses que circulavam no período demarcado; além disso, também foram consultados os seguintes periódicos semanais específicos do meio turfístico da cidade: Semanário Turfista, Equi, Canter e Supplemento; após coletados, as notícias veiculadas nestes foram classificadas a partir do editorial, da reportagem e do conteúdo. Além disso, foi realizada uma revisão bibliográfica em livros, artigos científicos, dissertações e teses, visando abordar o contexto histórico da cidade no recorte temporal deste estudo. As informações obtidas foram submetidas à análise documental, de acordo com Bacellar (2010) e Pimentel (2001), tendo como referencial teórico Elias e Guttmann. O resultado da análise das informações coletadas nas fontes é apresentado no tópico que segue.

\section{A prática do turfe como lazer}

Até meados do século XIX, os sul-rio-grandenses estavam acostumados a cavalos rústicos e à realização de disputas em canchas retas. Conforme Rozano e 
Fonseca (2005), em 1856, ano em que foi registrada a primeira importação oficial de um puro-sangue-inglês no Rio Grande do Sul, viu-se chegar o primeiro animal mais nobre e veloz. Procedentes da Inglaterra, estes cavalos chegaram a bordo do vapor Avon pela iniciativa do criador de cavalos José Ferreira Porto. A partir de então, foram dados os primeiros passos para o desenvolvimento e aperfeiçoamento da criação de cavalos no Estado.

Bissón (2008) alerta para o fato de que a Inglaterra era o parceiro comercial de maior importância do Brasil na época. Ressalta-se que, durante o século XIX, a Inglaterra foi a maior potência não somente econômica como também militar do mundo. A cultura inglesa, os costumes e hábitos estabeleciam uma relação com a elite brasileira, o que inclui o entusiasmo pelas corridas de cavalos. O turfe, no continente europeu, era considerado o esporte dos reis, já que muitas monarquias (Espanha, Inglaterra, Itália e França) sempre foram entusiastas dos cavalos (DUARTE, 2000).

Há indícios da influência dos novos tempos na prática do turfe em Porto Alegre em uma reportagem da Gazeta de Porto Alegre de 1880, por ocasião da inauguração do primeiro hipódromo da cidade:

[...] a civilisação ${ }^{6}$ tem suas exigencias; os usos do seculo passado não servem para o nosso seculo; uma populosa cidade, como a nossa, deve possuir um club de corridas, em que o estrangeiro possa reconhecer o systema usual em todos os paízes (INAUGURAÇÃO [...], 1880, p. 1).

A notícia publicada manifesta a preocupação com a fundação de um "club de corridas" que seguisse o modelo internacional. Para tanto, enfatiza o cumprimento de regras, as quais, conforme Guttmann (1978), passam a ser universais no esporte moderno. Gradualmente, os regulamentos tornam-se aceitos em todos os lugares.

\footnotetext{
${ }^{6}$ Nas citações literais, optou-se por manter a grafia original do período, a fim de não descaracterizar ou alterar o sentido contido na fonte primária.
} 
O surgimento dos prados acabou contando com a contribuição das condições criadas mais ao final do século XIX, em Porto Alegre, com o novo quadro viário da cidade e a transição dos arraiais/arrabaldes a bairros. Tais prados, além de aprimorar, com pistas circulares ou elípticas, as antigas carreiras de cancha reta, também colaboraram para o desenvolvimento dos bairros em que se localizavam. A prática equestre primitivamente esportiva das carreiras de cancha reta, portanto, teve seu processo histórico acompanhando o processo de modernização de Porto Alegre e de sua população (PEREIRA; LYRA; MAZO, 2010).

Práticas esportivas, assim como as corridas de cavalos, eram desenvolvidas neste período na cidade. Estas últimas passavam por uma transição para o turfe, ou seja: as carreiras em cancha reta foram praticamente eliminadas, inclusive pelo fato destas não poderem acolher o imenso público formado à época (BISSÓN, 2008). Os hipódromos, por sua vez, locais apropriados para a prática do turfe, possuíam, em sua estrutura, arquibancadas ao redor da pista oval, circular ou elíptica, permitindo que toda a assistência pudesse visualizar as corridas em todo o seu percurso. $\mathrm{O}$ novo formato das pistas também admitia um número maior de competidores.

Nos domingos, uma das atrações esportivas e de lazer dos porto-alegrenses passou a consistir nas corridas de cavalos, a exemplo do que ocorria no Rio de Janeiro, de acordo com Melo (2009a). Nestas, os jóqueis se apresentavam bem vestidos, em espaços onde os integrantes da elite econômica, de procedência nomeadamente rural, podiam exercer o seu anseio de distinção, com seus suntuosos trajes. Esta prática esportiva, no país, neste período, parecia consistir em um espetáculo, propiciando à população uma oportunidade de observar e ser observada. Os hipódromos favoreciam a exibição da presença, em função de sua localização, disposição e, até mesmo, de sua 
estrutura física. Outro aspecto que pode compor parte de seu sucesso no período é o fato de consistir em um entretenimento nas cidades, necessitadas de alternativas deste caráter, uma vez que se tratava de uma atividade pública que admitia distinguir as diferenças de classe.

No contexto turfístico de Porto Alegre, também se pôde identificar indícios de burocratização da prática tão logo foram estabelecidos quatro hipódromos atuantes simultaneamente na cidade, na década de 1890: Hipódromo Boa Vista, Hipódromo RioGrandense, Hipódromo Navegantes e Hipódromo Independência (ROZANO; FONSECA, 2005). Cada um destes hipódromos constituía uma associação anônima, visando a lucros mercantis. Assim, conforme reportagem do Semanário Turfista, ao estarem em jogo altos interesses financeiros com os significativos valores que eram apostados em cada corrida, ocorriam atritos entre diretorias destas associações $(7 \mathrm{DE}$ SETEMBRO, 1930, p. 2).

Inaugurou-se, no dia primeiro de outubro de 1899, a primeira entidade que tentava minimizar os conflitos e proporcionar benefícios ao turfe: o Derby Club. Esta agremiação, a qual contava com representantes de todos os hipódromos, atuou no Hipódromo Independência, assim como mais tarde organizaria corridas no Hipódromo Boa Vista e no Hipódromo Rio-Grandense. Embora influente, o Derby Club não teve a duração esperada.

Ao receber o embate despertado pelo interesse dos integrantes dos demais hipódromos, descontentes com a situação, o Derby Club acabou por ser extinto e reaberto por várias vezes no meio social e esportivo de Porto Alegre, com distintos nomes. Em 1907, um grupo expressivo de turfistas fundou o Turf - Club, tendo sua sede no Hipódromo Rio-Grandense. Não obstante, esta sociedade nova também durou por 
pouco tempo, já que surgiu uma divergência entre seus organizadores, visando a instituir outra entidade. Ainda no mesmo ano, a proposta de organização de uma nova associação foi aceita e vingou como entidade representativa do turfe sul-rio-grandense de forma permanente: a Associação Protetora do Turf, a qual, em 1944, passa a constituir o Jockey Club do Rio Grande do Sul (ROZANO; FONSECA, 2005), vigente até os dias atuais.

A Associação Protetora do Turf foi organizada em sete de setembro de 1907, fundamentalmente pela elite luso-brasileira. Esta associação tinha o intuito de reanimar o turfe na cidade, o qual passava por uma crise na primeira década do século XX. Seus objetivos, registrados na ata histórica que oficializou a fundação, eram: promover a unificação e impulsionar o esporte hípico em Porto Alegre. De acordo com a ata, a Protetora surgia para unificar:

[...] elementos que pugnassem seriamente pelo engrandecimento do esporte atualmente em crise bem difícil. A nova associação será criada visando dividir entre jockeys, tratadores e inscritores os lucros líquidos que forem apurados em suas festas esportivas e empenhará a maior severidade pela máxima moralidade em suas corridas e festas esportivas (CANTEIRO, 1907, p. 1).

No princípio do século XX, com a fundação da Associação Protetora do Turf, se tem a intenção concretizada de promover e respeitar o turfe sob o ponto de vista esportivo, e não simplesmente lucrar com este esporte. A mobilização em torno do turfe porto-alegrense passa, então, a configurar-se como uma expressão do associativismo esportivo (PEREIRA, 2012).

Com relação à reflexão acerca da igualdade de acesso à participação da competição, Guttmann (1978) já alertava para a existência de restrição de classe em meio às corridas de cavalos desde o século XVII nos Estados Unidos da América. No turfe norte-americano, em algumas corridas, no quartel final do século XIX, constatava- 
se que, dentre 15 jóqueis, 14 eram negros. Porém, ainda no mesmo período, foram expulsos desta ocupação que lhes fornecia o sustento. Ao remeter-se a Porto Alegre, as reportagens de jornais e da Revista do Globo, ao mencionarem características dos jóqueis, não fazem referência à cor da pele dos mesmos. Corroborando com tal silêncio das fontes, as imagens das reportagens tampouco nos podem elucidar acerca disto. Além da baixa qualidade de definição das imagens dificultar a identificação, a opção da maioria dos autores das fotos era reservar o foco de tais registros preferencialmente para os cavalos em detrimento do jóquei.

Tal fato repetia-se nos textos das reportagens jornalísticas e da Revista do Globo, os quais, predominantemente, realçavam a vitória e o sucesso dos cavalos ao invés do conjunto jóquei-cavalo. Esta posição das publicações parece estar em consonância com a declaração do jóquei Mário Oliveira, em reportagem da Revista do Globo, o qual reforça a maior importância do cavalo no conjunto jóquei-cavalo para uma prática bem sucedida no turfe:

Muitas vezes está dependendo do jockey a vitória de um cavalo e, consequentemente, o dinheiro de muita gente. O jockey, depois do cavalo, é o instrumento mais importante numa corrida. É preciso saber conduzir o animal (TALHA, 1939, p. 36).

O fragmento "é preciso saber conduzir o animal", extraído do depoimento de Mário Oliveira, corrobora com o estudo de Bjarke Rink (2008) sobre a relação homemcavalo e suas consequências históricas. Ao confirmar o aspecto "físico" dos esportes equestres, este autor afirma que os mesmos provocam a plena atividade do cérebro humano, desafiando não somente os sentidos, a propriocepção, a flexibilidade e os movimentos, mas também a própria capacidade de liderar. A capacidade de tomada de decisões constitui a principal contribuição do ser humano para o conjunto cavalocavaleiro na equitação. 
Um ser humano que comanda os movimentos de um animal que pesa, em média, $500 \mathrm{~kg}$, e que, para isto, necessita administrar, por meio de seu sistema nervoso, as ações de um cérebro como o do cavalo, estruturado para mobilizar um organismo muitas vezes mais potente do que o do homem, demonstra a importância de sua ação na prática equestre. Em outras palavras, não basta possuir um cavalo com ótimas qualidades para determinada prática esportiva; é necessário possuir um cavaleiro/amazona (jóquei/joqueta, no caso do turfe) que saiba conduzir tais virtudes do animal para um bom desempenho do conjunto no esporte.

No que se refere ao contexto brasileiro do turfe, tanto historicamente quanto no momento atual, a origem dos jóqueis e joquetas, em sua maioria, é das classes populares (ADELMAN; MORAES, 2008). Desde os primórdios do turfe no Brasil, os primeiros jóqueis apresentavam uma origem humilde e a sua participação esportiva se instituía como o exercício de uma profissão, por meio da qual se poderia ascender socialmente (MELO, 1998). Por outro lado, a assistência, os proprietários de animais e os apostadores, em geral, pertenciam às camadas mais privilegiadas economicamente. Para estes, as representações desta prática associavam-se, conforme argumenta Rodrigues (2006), à distinção que ela poderia proporcionar não apenas para aqueles que a prestigiassem, com as suas elegantes e apuradas indumentárias, a exemplo dos eventos ingleses e franceses, mas também para a cidade que a promoveria. Em reportagem da Revista do Globo de 1939, pode-se verificar tal desejo de identificação com a elegância da sociedade e da cidade:

O turf constituiu sempre um dos mais elegantes esportes das grandes cidades, Paris, Londres, Buenos Ayres, Rio de Janeiro e outras fazem de seus hipódromos o ponto de reunião de sua elite, em que as figuras de relevo da política, das artes e do comércio fazem do turf o esporte predileto (TURF, 1939, p. 36). 
Especificamente em Porto Alegre, as tribunas oficiais dos hipódromos acomodavam um público tão conexo com as elites econômicas da cidade que, frequentemente, até o presidente do Estado prestigiava as disputas turfísticas e fazia-se ali presente também, como exemplificado em uma reportagem da Revista do Globo (A GRANDE..., 1929). Cabe ressaltar que o turfe, segundo Adelman e Moraes (2008, p. 23), congregava um "trânsito entre 'dois mundos"”, na medida em que, concomitantemente, constituía lazer para alguns e trabalho para outros. Enquanto as elites econômicas vislumbravam um local de diversão, distração e desfile de elegância e distinção nos hipódromos, as camadas mais populares/trabalhadoras os tinham como oportunidades de sustento e consequente ascensão social e econômica. Conforme Damo (2002), no seu estudo acerca do futebol, a conformação esportiva do amadorismo e do profissionalismo neste esporte seguiu determinados caminhos.

No processo de "democratização funcional" 7 do futebol, com a entrada das classes trabalhadoras neste esporte, as elites econômicas passaram a perceber tais classes como uma ameaça abarcando questões de identidade e prestígio social. Damo (2002) mostra que as elites modificaram a prática do amadorismo para uma ideologia e se recolheram nas sociedades e ligas que lhes ofereceram base, enquanto que aqueles que preferiram, primeiramente, vincular-se ao profissionalismo, acabaram migrando para o domínio administrativo das ligas e clubes. De tal modo, foram capazes de se perpetuar, mesmo que como um grupo limitado e com autoridade política, assumindo a responsabilidade de projetar, desenvolver, regulamentar, por fim, raciocinar sobre o futebol. Esta análise mobilizou uma reflexão no âmbito do turfe.

\footnotetext{
7 A noção de "democratização funcional" é apresentada ao fazer menção ao ingresso das camadas operárias aos esportes modernos. Trata-se de uma ação de massificação/popularização/democratização dos esportes burgueses, simultânea à estabilização do Estado e do avanço progressivo das cadeias de interdependência entre sujeitos e grupos (DAMO, 2002; ELIAS, 1992).
} 
Apesar de o turfe ter preservado seus valores aristocráticos - a prática como um fim em si mesmo - pelas classes mais privilegiadas economicamente, admitia profissionais $^{8}$ (jóqueis, tratadores e treinadores de cavalos) que necessitavam ser recompensados financeiramente pelo tanto que deixavam de receber ao trocar outros trabalhos pelo esporte. Isto demonstra mais um elemento de esportivização, com a especialização das funções do atleta/jóquei profissionalizando-se (GUTTMANN, 1978). Simultaneamente, os hipódromos eram administrados pela elite econômica, por meio de associações e entidades anônimas, as quais visavam, também, a lucros mercantis (ROZANO; FONSECA, 2005).

Em seus primórdios, tem-se que, para jóqueis e joquetas, ou seja, praticantes das camadas populares, o turfe representava e ainda representa uma atividade profissional. Vislumbra-se, aí, a possibilidade deste engajamento profissional representar, para os jóqueis, a tentativa de uma mobilidade social vertical ascendente, caso estes jóqueis alcancem vitórias. Ou seja, ao conquistar prêmios, estes praticantes do turfe teriam uma oportunidade para circular entre categorias e classes sociais. Caso contrário, para os jóqueis que não atingem vitórias nas disputas, tal mobilidade não seria concretizada e estes permaneceriam na reprodução social. $O$ jóquei sem conquistas segue permanecendo à classe popular, sendo simplesmente mais um praticante de turfe qualquer, que deve empenhar-se por meio de seu esforço físico para atingir reconhecimento e capital (econômico, social, simbólico).

\footnotetext{
${ }^{8}$ Até os dias atuais, a profissão de "jóquei" segue representando a oportunidade de sustento de muitas famílias. Além do fato de a remuneração ser relativamente baixa, este ofício ainda exige determinados atributos físicos, tais como: estatura de até, aproximadamente, $1 \mathrm{~m} 60 \mathrm{~cm}$, e peso máximo correspondente ao adequado para tal estatura. Uma reportagem do jornal Zero Hora exemplifica tal situação, apresentando um ex-jóquei que, por não ter cumprido com os requisitos físicos exigidos pelo esporte ao atingir a fase adulta, teve que abandonar a profissão, passando a ser carroceiro pelas ruas de Porto Alegre para poder prover a sobrevivência de sua família (JÓQUEI..., 2008, p. 29).
} 
Concomitantemente, para a assistência, integrante da classe alta e média alta, significa a possibilidade da prática pelo amadorismo, isto é, pelo puro prazer da prática em si. Constitui-se em mais uma estratégia mobilizada para a reprodução da ordem social, conservando-se ou apropriando-se de capital social e simbólico, especialmente. Tal fato pode estar relacionado, ainda, com o que Jesus (1999) relata acerca da sociedade brasileira no período de auge do turfe, a qual apresentava um forte preconceito no que se refere às atividades que exigiam esforço muscular; qualquer prática corporal que fosse mais exigente era considerada como degradante da moral.

Era esperado, dos homens, que cuidassem do intelecto e dos negócios, e não do corpo. Os exercícios físicos eram, frequentemente, considerados prejudiciais à saúde e tinham um valor menor se comparados às atividades intelectuais (MELO, 2006). Aqueles responsáveis pela condução dos cavalos, os jóqueis, eram, em geral, integrantes das camadas populares ou estrangeiros contratados. Excepcionalmente, um membro das "melhores famílias" participava das provas, em festivais beneficentes ou datas comemorativas; assim, seria preservado o caráter essencial da prática esportiva. O turfe atingia, também, grandes movimentos financeiros e fortunas à época.

O período (1892-1894) representou o auge do turfe porto-alegrense, tendo esta prática ocupado um espaço de destaque no cenário esportivo da cidade. É importante realçar que a identidade do turfe estava muito relacionada à sociedade aristocrática rural. Porém, com o surgimento de novos focos de interesse, tais como o futebol, o cinema, bem como com a concorrência significativa entre prados e sociedades turfísticas, uma crise à prática turfística foi gerada. A mudança nas características valorizadas pela nova cultura burguesa em formação, e a crise econômica advinda da Revolução Federalista, também contribuíram para a consolidação deste período de 
decadência no turfe porto-alegrense. A fundação da Associação Protetora do Turf foi uma estratégia para recuperar esta prática na cidade. Assim, da pluralidade de prados, o turfe partiu para a unificação, visando a consolidar o respeito pelo seu caráter esportivo.

A prática do turfe atraía muitas pessoas ao hipódromo da Associação Protetora do Turf - o Hipódromo Independência ${ }^{9}$, o único remanescente após a unificação do turfe em uma única entidade. Desta maneira, passa a ser perceptível a concreta decisão de impulsionar e respeitar o turfe como uma prática esportiva, e não simplesmente como um jogo de azar. A partir de então, se pode perceber outra postura frente às corridas de cavalos. Testemunha-se uma mobilização pelo turfe com configurações e expressões de uma associação esportiva (PEREIRA; SILVA; MAZO, 2010). A Associação Protetora do Turf contava, frequentemente, com a presença de autoridades, como o presidente do Estado no final da década de 1920, Getúlio Vargas, e sua esposa, assim como a miss Rio Grande do Sul, etc. (NAS CORRIDAS..., 1929). Getúlio Vargas é citado como “incentivador apaixonado" por todos os esportes em que o cavalo, tão necessário na paz como na guerra, é fator colaborador com o homem, como o turfe e o hipismo (NOVOS..., 1938, p. 20). Com base nestas informações, evidencia-se que o turfe era uma prática esportiva vinculada à elite porto-alegrense, sendo este um meio de atrair olhares.

A elite passou a preferir o turfe como seu esporte predileto neste período. A tradição desta elite rural na criação de cavalos, possivelmente, foi um dos fatores que favoreceu a fundação dos primeiros prados em Porto Alegre. Na obra “Álbum d'O Rio

\footnotetext{
${ }^{9}$ Ao configurar-se como o único centro turfístico da cidade, o local logo se tornou acanhado e obrigou o Jockey Club do Rio Grande do Sul a procurar novas instalações. O Jockey cedeu espaço para o Parque Moinhos de Vento, o Parcão, e o Hipódromo Independência foi transferido para o Bairro Cristal, onde se situa até os dias atuais. Todavia, a transferência ocorreu somente em 5/11/1959. No Bairro Cristal, o hipódromo passou a apresentar uma arquitetura atraente, além de duas pistas, uma de grama e outra de areia. Foi inaugurado em 22/11/1959 (ROZANO; FONSECA, 2005).
} 
Grande do Sul Sportivo", organizada por Lemos e Carvalho (1919) as 12 páginas iniciais são dedicadas a um texto intitulado "O Cavallo", no qual são destacados os criadores de cavalos com fotogravuras que parecem representar figuras heroicas. A maioria dos criadores de cavalos era constituída de portugueses e luso-brasileiros, fato que pode ser constatado na listagem de nomes relacionados: Pedro Jobim Ferreira Porto, Ramiro Fortes Barcelos e Luiz Manoel de Azevedo. Estes homens eram médicos, militares, conselheiros e industrialistas, que integravam a elite sul-rio-grandense ligada à vida rural.

Com relação à nova postura assumida diante do turfe, a de vislumbrá-lo enquanto um esporte, existia uma preocupação com a igualdade de condições de competição na década de 1930, na medida em que se procurava fazer com que todos os cavalos corressem com um peso exato sobre o seu dorso (TALHA, 1939, p. 37). Caso o jóquei de um cavalo, juntamente com a sela, não atingisse tal peso, acrescentavam-se chumbos à sela, como até os dias atuais costuma-se proceder nestas competições. Outra evidência localizada nas fontes, a qual também demonstra esta preocupação com a igualdade de condições nas disputas turfísticas, diz respeito ao emparelhamento da pista de areia, o qual era realizado após cada páreo (TALHA, 1939, p. 37). Tal ação era levada a cabo por meio de um conjunto de dois muares, os quais tracionavam um gradil com o intuito de nivelar o máximo possível a pista de competições, constituindo, deste modo, mais um indício de esportivização nesta prática equestre.

O turfe porto-alegrense, na década de 1940, contava com tecnologia a seu favor. Em reportagem da Revista do Globo, há um parágrafo dedicado à explanação do emprego do cronômetro no cotidiano de treinos das corridas de cavalos, em que "o bom tratador nunca pode se divorciar do cronômetro" (RIBEIRO, 2004, p. 26). A prática do 
turfe, paulatinamente, ia adequando-se à ideia de que "[...] o esporte deveria ser definido como uma atividade física que pode ser medida em pontos ou no sistema c-g-s (centímetro - grama - segundo)" (GUTTMANN, 1978, p. 47). As estatísticas do turfe, em Porto Alegre, representavam elementos ou componentes das estatísticas da sociedade moderna.

Na prática do turfe porto-alegrense, nas fontes localizadas, também se observam passagens que registram recordistas. Contudo, tais recordistas não são os jóqueis, mas sim os cavalos. Os periódicos semanais específicos do meio turfístico da cidade destacavam as conquistas dos animais, em especial no que se refere tanto à sua quantidade de vitórias como ao tempo necessário para percorrer toda a extensão da pista, o qual diminuía com regularidade, isto é, a noção de recorde. Este é o caso do semanário de turfe intitulado Canter. Em 1939, este periódico publicava, com ênfase, o fato de que o cavalo Maritain, o qual já havia desempenhado uma prodigiosa campanha em pistas argentinas, encontrava-se em solo porto-alegrense para a disputa do Grande Prêmio Bento Gonçalves, a prova mais importante do turfe sul-rio-grandense. Tamanho realce dedicado à presença deste animal devia-se, conforme a publicação, à participação doeste que era o "Derrubador de recordes em São Paulo e no Rio" (G.P. BENTO GONÇALVES..., 1939, p. 81).

O treinador deste cavalo, na mesma edição do semanário, afirmou que "[...] Maritain derrubará mais esse recorde, que já é seu" (G.P. BENTO GONÇALVES..., 1939, p. 81), referindo-se ao alcance de uma marca estabelecida por ele próprio, no ano de 1937, na pista de corridas do prado Moinhos de Vento. Este cavalo era conhecido dos turfmen $^{10}$ porto-alegrenses desde o final de 1937, quando era propriedade de sul-rio-

\footnotetext{
${ }^{10}$ Designação para todos que se envolviam com o turfe, como jóqueis, dirigentes ou unicamente como assistência entusiasta (MELO, 2007).
} 
grandenses. Neste referido ano, Maritain havia vencido o Grande Prêmio Bento Gonçalves, com uma facilidade notável, “[...] quando teve a oportunidade de estabelecer o recorde da maior distância corrida em nosso turfe" (G.P. BENTO GONÇALVES..., 1939, p. 82). Anos mais tarde, este cavalo foi vendido para um proprietário de São Paulo, onde começou um longo caminho de conquistas em disputas nos dois maiores hipódromos do Brasil, localizados em São Paulo e no Rio de Janeiro. O desempenho deste cavalo correspondia a uma sequência de significativas vitórias alcançadas sobre animais de reconhecido valor nos principais centros turfistas do continente.

O periódico Supplemento, também dedicado ao turfe, em 1939, anunciava a chegada de Maritain para o Grande Prêmio Bento Gonçalves como o "Derrubador de Records" (VEM CORRER..., 1939, p. 11). Registrava que, no mês anterior à competição, Maritain “[...] havia estabelecido mais um record para os 2.800 metros" (VEM CORRER..., 1939, p. 11). Como justificativa para esta atuação, referia sua condição de "[...] um dos cinco maiores 'performers' das pistas brasileiras, recordista na Gávea [Rio de Janeiro] e na Mooca [São Paulo], nos Moinhos de Vento [Porto Alegre] e laureado em nossa prova máxima [G.P. Bento Gonçalves]” (MARITAIN..., 1939, p. $8)$.

Assim, ao analisar-se o turfe em Porto Alegre, com base no conceito de esporte desenvolvido por Guttmann (1978), pode-se afirmar que se trata de uma prática esportiva equestre. Desde a organização dos primeiros prados da cidade, observam-se manifestações das características propostas pelo autor para classificar uma prática como tal. Assim como anteriormente havia ocorrido com as carreiras de cancha reta, a utilização do cavalo no lazer é apropriada; mas, desta vez, conformando um esporte: o turfe. 
Os prados constituíram "um fenômeno transitório e surpreendente na cidade, pois com o novo século os espaços do turfe cederiam seu lugar aos do futebol" (FRANCO, 2000, p. 91). Os hipódromos também foram cedendo espaço para outros empreendimentos em Porto Alegre, como, por exemplo, edificações. As primeiras décadas do século XX assinalam um período efervescente em Porto Alegre, uma vez que abarcaram o advento do capitalismo, a chegada significativa de imigrantes europeus, a acentuação no processo de industrialização, a urbanização e a emergência de novas classes - a burguesia e o incipiente proletariado.

A cidade passava por transformações sociais, políticas e econômicas, que repercutiram na ocupação de seus espaços. Consequentemente, novos modelos para homens e mulheres, condizentes com um incipiente cenário que se impunha, passaram a ser importados de outras metrópoles, especialmente do Rio de Janeiro, capital do país no momento, e que passava por aceleradas transformações nas condutas dos habitantes, devido ao, dentre outros fatores, considerável desenvolvimento tecnológico. Conforme Melo (2006, p. 7), “o papel de metrópole polarizadora cabe perfeitamente ao Rio de Janeiro, que passa a redimensionar e ditar (ainda mais) modas, comportamentos, sistemas de valores, formas de viver". Em consonância com esta conjuntura capitalista, uma inspiração político-filosófica positivista, com seus anseios de ordem, progresso e modernidade, passa a constituir a vitrine da cidade, concretizada não somente no estilo arquitetônico dos prédios, mas também nos valores cultivados.

Em meio à rápida modernização de Porto Alegre, surgiram, também, associações esportivas, ou seja, sociedades, ligas, clubes e federações dedicadas à organização ou promoção de práticas corporais e esportivas (MAZO, 2003). Estas, paulatinamente, passariam a ser orientadas como um meio para a constituição de corpos dispostos a 
tratar a representação capitalista como valor ético primordial. As novas práticas passam a enfraquecer as carreiras de cancha reta e o turfe, apesar de outrora, na última década do século XIX, terem representado uma das principais formas de lazer da população da capital, como atesta Franco (1998): “o prado era o estádio de futebol do portoalegrense" (p. 103). As citadas práticas equestres não mais condiziam com a nova ordem que se aproximava: o moderno, o urbano, a força no físico humano e não mais o arcaico, agrário e patriarcal esporte representativo da força animal.

Neste momento, houve uma diminuição das imposições de caráter moral no que se refere à exibição do físico, sendo desenvolvida a notoriedade das práticas nas quais o movimento humano é o item principal. Tratam-se, aqui, do remo, assim como da natação e do atletismo. Estes esportes aproximam-se mais daquilo que atualmente se idealiza, genericamente, para a prática esportiva: desafio, superação, higiene, saúde (MELO, 2009b).

Outro aspecto que também tem relação com a desaceleração do turfe diz respeito à identidade desta prática esportiva equestre, eminentemente relacionada à sociedade aristocrática rural e que passa a confrontar com a cultura burguesa em formação. Esta nova classe social passou a atacar o turfe devido ao seu caráter de jogo, já que os burgueses identificavam-se com o remo, o ciclismo, o futebol, incorporando a modernidade da virada do século (MELO, 2006). Processo semelhante é apresentado por Melo (1999), no Rio de Janeiro, onde o turfe e o remo também disputavam a prioridade no espetáculo urbano em fins do século XIX, representando, na esfera esportiva, a transição do patriarcado da oligarquia agrária brasileira para uma sociedade urbana, moderna e europeizada. 


\section{Considerações finais}

As fontes consultadas evidenciaram que, em Porto Alegre, a prática do hipismo tem seus primórdios na década de 1910, no contexto militar. A prática equestre do salto do hipismo, em Porto Alegre, emerge em um contexto restrito aos policiais e oficiais militares e expande-se para a parcela civil da população, aproximando-se da igualdade de acesso para compor um esporte moderno. Contudo, tal característica, inerente a um esporte moderno, expressava-se de uma forma muito particular e com limitações no contexto do hipismo de Porto Alegre, entre as décadas de 1920 a 1940. Isto porque as fontes consultadas apontaram para um acesso a tal prática restrito aos detentores de capital social e econômico da cidade.

Nesta mesma linha, subsídios referentes a um processo de esportivização, mais especificamente a uma especialização de funções, também já podiam ser identificados no contexto do hipismo. Emerso no ambiente de caserna, na Brigada Militar em Porto Alegre, o salto do hipismo desde seus primórdios já demandava mais funções além dos oficiais cavaleiros, os quais se dedicavam à prática. Eram necessários ferradores, seleiros, dentre outros; além disto, eram demandados, também, instrutores, os quais, predominantemente, neste período, provinham do meio militar e, muitas vezes, eram estrangeiros que traziam sua experiência da equitação de referência militar europeia.

$\mathrm{Na}$ prática do salto do hipismo em Porto Alegre, também há indícios de um caminho tecnológico da quantificação na década de 1930, quando os certames eram decididos com base no tempo e na quantidade de faltas cometidas pelos conjuntos cavaleiros-cavalos. Tal tipo de ocorrências nas práticas esportivas da cidade sugere uma relação com o contexto de uma cidade que se contagiava pelos ares da modernidade, com padrões e valores de diversas metrópoles. 
No contexto hípico porto-alegrense, no período do estudo, as fontes localizadas sugerem a ocorrência de recordes com relação ao número de conquistas de títulos em competições. No contexto do salto do hipismo porto-alegrense, os recordes são registrados por meio do destaque às conquistas do cavaleiro/amazona, ao passo que, no turfe, as marcas de recorde são armazenadas pelos êxitos dos cavalos.

O surgimento dos prados acabou contando com a contribuição das condições criadas ao final do século XIX em Porto Alegre, com o novo quadro viário da cidade e a transição dos arraiais/arrabaldes a bairros. Os prados, além de aprimorar, com pistas circulares ou elípticas, as antigas carreiras de cancha reta, também contribuíram para o desenvolvimento dos bairros em que se localizavam. No contexto turfístico de Porto Alegre, também se pôde identificar indícios de burocratização tão logo foram estabelecidos quatro hipódromos atuantes simultaneamente na cidade, na década de 1890. Cada um destes hipódromos constituía uma associação anônima, visando a lucros mercantis. Assim, ao estarem em jogo altos interesses financeiros com os significativos valores que eram apostados em cada corrida, ocorriam atritos entre diretorias destas associações. No princípio do século XX, com a fundação da Associação Protetora do Turf, se tem a intenção concretizada de promover e respeitar o turfe sob o ponto de vista esportivo, e não simplesmente lucrar com este esporte.

Com relação à igualdade de acesso às competições turfísticas, tem-se que a origem dos jóqueis era, em sua maioria, de pessoas oriundas das classes populares. Desde os primórdios do turfe no Brasil, os primeiros jóqueis apresentavam uma origem humilde e a sua participação esportiva se instituía como o exercício de uma profissão, por meio da qual se poderia ascender socialmente. Por outro lado, a assistência, os proprietários de animais e os apostadores, em geral, pertenciam às camadas mais 
privilegiadas economicamente. Para estes, as representações desta prática associavamse, à distinção que ela poderia proporcionar não apenas para aqueles que a prestigiassem, com as suas elegantes e apuradas indumentárias, a exemplo dos eventos ingleses e franceses, mas também para a cidade que a promoveria.

Apesar de o turfe ter preservado seus valores aristocráticos pelas classes mais privilegiadas economicamente, admitia profissionais (jóqueis, tratadores e treinadores de cavalos) que necessitavam ser recompensados financeiramente pelo tanto que deixavam de receber ao trocar outros trabalhos pelo esporte. Isto demonstra mais um elemento de esportivização, com a especialização das funções do atleta/jóquei profissionalizando-se.

Com relação à nova postura assumida diante do turfe no contexto portoalegrense, a de vislumbrá-lo enquanto um esporte, existia uma preocupação com a igualdade de condições de competição na década de 1930, na medida em que já se procurava fazer com que, por exemplo, todos os cavalos corressem com um peso exato sobre o seu dorso. Outra evidência que também demonstra esta preocupação com a igualdade de condições nas disputas turfísticas, diz respeito ao emparelhamento da pista de areia, o qual era realizado após cada páreo. Tal ação constitui mais um indício de esportivização nesta prática equestre.

De tal modo, o turfe porto-alegrense, na década de 1940, já contava, inclusive, com tecnologia a seu favor. O emprego do cronômetro no cotidiano de treinos das corridas de cavalos exemplificava bem a presença da quantificação na prática turfística. As estatísticas do turfe, em Porto Alegre representavam elementos ou componentes das estatísticas da sociedade moderna em questão no período. 
$\mathrm{Na}$ prática do turfe porto-alegrense, também se observam passagens que registram recordistas. Contudo, tais recordistas não são os jóqueis, mas sim os cavalos. Deste modo, os periódicos semanais específicos do meio turfístico da cidade destacavam as conquistas dos animais, em especial no que se refere tanto à sua quantidade de vitórias como ao tempo necessário para percorrer toda a extensão da pista, o qual diminuía com regularidade, isto é, a noção de recorde.

Contudo, os hipódromos também foram cedendo espaço ao desenvolvimento de Porto Alegre, sendo tomados parcelados em loteamentos e ocupados por edificações. As primeiras décadas do século XX assinalam um período efervescente em Porto Alegre, uma vez que abarcou o advento do capitalismo, a chegada significativa de imigrantes europeus, a acentuação no processo de industrialização, a urbanização e a emergência de novas classes - a burguesia e o incipiente proletariado. A cidade, portanto, passava por transformações sociais, políticas e econômicas, isto é: os ares da modernização atingiam a cidade.

Em meio à rápida modernização de Porto Alegre, surgiram, também, associações esportivas, ou seja, sociedades, ligas, clubes e federações dedicadas à organização ou promoção de atividades ligadas a uma ou mais práticas esportivas, as quais, paulatinamente, passariam a ser orientadas como um meio para a constituição de corpos dispostos a tratar a representação capitalista como valor ético primordial. Tais práticas passam a enfraquecer os esportes equestres das carreiras de cancha reta e do turfe. Portanto, apesar de outrora, na última década do século XIX, as corridas de cavalos terem representado uma das principais formas de lazer da população da capital, já não mais condiziam com a nova ordem que se aproximava: o moderno, o urbano, a força no 
físico humano e não mais o arcaico, agrário e patriarcal esporte representativo da força animal.

\section{REFERÊNCIAS}

ADELMAN, M.; MORAES, F. A. Tomando as rédeas: um estudo etnográfico da participação feminina e das relações de gênero no turfe brasileiro. Esporte e Sociedade. Rio de Janeiro, UFF. Ano 3, n. 9, Jul.2008/Out.2008, p.1-29. Disponível em: $<$ http://www.uff.br/esportesociedade/pdf/es903.pdf $>$ Acesso em: 05 jul. 2011.

BACELLAR, C. Fontes documentais: uso e mau uso dos arquivos. In: PINSKI, C. (Org.). Fontes históricas. São Paulo: Contexto, 2010, p. 23 - 80.

BISSÓN, C. A. Moinhos de Vento: histórias de um bairro de elite de Porto Alegre. Porto Alegre: Secretaria Municipal da Cultura: IEL, 2008.

CAMPEONATO Nacional de Cavalo D'armas. 23/11/1935, n. 172, p. 40. In: MAZO, J.Z. O Esporte e a Educação Física na Revista do Globo: Catálogo 1929-1967. Porto Alegre: FEFID/PUCRS; ESEF/UFRGS, 2004, CD-ROM.

CANTEIRO, O. Ata Inaugural da Associação Protetora do Turfe. Porto Alegre, 1907, p.1.

NAS CORRIDAS da Protectora do Turf. 20/04/1929, n. 7, p. 33. In: MAZO, J.Z. O Esporte e a Educação Física na Revista do Globo: Catálogo 1929-1967. Porto Alegre: FEFID/PUCRS; ESEF/UFRGS, 2004, CD-ROM.

DAMO, A. S. A Emergência do Associativismo Esportivo e do Futebol. In: DAMO, A.S. Futebol e identidade social: uma leitura antropológica das rivalidades entre torcedores e clubes. Porto Alegre: Ed. Universidade/UFRGS, 2002, p.16-32.

DEL PRIORE, M. "Jogos de cavalheiros": as atividades físicas antes da chegada do esporte. In: DEL PRIORE, M.; MELO, V.A. (Org.). História do Esporte no Brasil: do império aos dias atuais. São Paulo: Editora UNESP, 2009, p.13-33.

DUARTE, O. História dos Esportes. São Paulo: MAKRON Books, 2000.

ELIAS, N. A gênese do desporto: um problema sociológico. In: ELIAS, N.; DUNINNG, E. A Busca da Excitação. Lisboa: Difel, 1992, p. 187-221.

FESTA Hípica no Country Club. 29/05/1943, n. 340, p. 38. In: MAZO, J.Z. O Esporte e a Educação Física na Revista do Globo: Catálogo 1929-1967. Porto Alegre: FEFID/PUCRS; ESEF/UFRGS, 2004, CD-ROM.

A FESTA de amanhã. Seção Vida Desportiva. Hippismo. Sociedade Hippica RioGrandense. Diário de Notícias. Porto Alegre, 6 julho 1929, p. 5. 
FRANCO, S.C. Porto Alegre: guia histórico. 3. ed. Porto Alegre: UFRGS, 1998.

Gente e espaços de Porto Alegre. Porto Alegre: UFRGS, 2000.

G.P. BENTO GONÇALVES: a sua disputa durante três decênios - reminiscências e curiosidades. Canter - Semanário de Turfe. Porto Alegre: Ed. Banco Nacional do Comércio, 04/11/1939, p.81-94.

A GRANDE corrida de domingo. 1929, n.21, p.30. In: MAZO, J.Z. O Esporte e a Educação Física na Revista do Globo: Catálogo 1929-1967. Porto Alegre: FEFID/PUCRS; ESEF/UFRGS, 2004, CD-ROM.

GUTTMANN, A. From ritual to Record: the nature of modern sports. New York: Columbia University, 1978.

INAUGURAÇÃO do Hippodromo. Gazeta de Porto Alegre. Porto Alegre, 13 maio 1880, p.1.

JESUS, G. M. Construindo a Cidade Moderna: a Introdução dos Esportes na Vida Urbana do Rio de Janeiro. Estudos Históricos, Rio de Janeiro, n. 23, p. 17-39, 1999. Disponível em:

http://bibliotecadigital.fgv.br/ojs/index.php/reh/article/view/2086/1225>. Acesso em: 27 mai. 2014.

JÓQUEI virou carroceiro. Zero Hora. Porto Alegre, 13 maio 2008, p.29.

LEMOS, A.; CARVAlHO, E. (Org.). Álbum d'O Rio Grande do Sul Sportivo. Porto Alegre: Livraria do Globo, 1919.

MARITAIN, Meulen, Ouroforte, Bonsol e Aboukir são os grandes azes que disputarão amanhã na raia dos Moinhos de Vento, o Derby rio-grandense. Supplemento. Porto Alegre, 04/11/1939, p.8-9.

MAZO, J.Z. Emergência e a Expansão do Associativismo Desportivo em Porto Alegre (1867-1945): espaço de representação da identidade cultural teuto-brasileira. 2003. Tese Doutorado. Faculdade de Educação Física e Ciências do Desporto, Universidade do Porto, Portugal. Disponível em: < http://hdl.handle.net/10183/18673>. Acesso em: 26 mai. 2014.

MELO, V.A. Possíveis representações sobre o turfe na sociedade carioca do século XIX. Lecturas Educación Física y Deportes. Buenos Aires, ano 3, n. 9, março 1998. Disponível em: < http://www.efdeportes.com/efd9/turf91p.htm>. Acesso em: 17 jan. 2011.

- História da educação Física e do Esporte no Brasil: panorama e perspectivas. São Paulo: IBRASA, 1999.

. Remo, Modernidade e Pereira Passos: primórdios das políticas públicas de esporte no Brasil. Esporte e Sociedade. Rio de Janeiro, UFF. N. 3, jul/out 2006. 
Disponível em: < http://www.uff.br/esportesociedade/pdf/es305.pdf $>$. Acesso em: 17 jan. 2011.

. Dicionário do esporte no Brasil: do século XIX ao início do século XX. Campinas: Autores Associados, 2007.

MELO, V. A. Corpos, bicicletas e automóveis: a transição dos séculos XIX e XX. In: DEL PRIORE, M.; MELO, V.A. (Org.). História do Esporte no Brasil: do império aos dias atuais. São Paulo: Editora UNESP, 2009a, p.71-105.

- Das touradas às corridas de cavalo e regatas: primeiros momentos da configuração do campo esportivo no Brasil. In: DEL PRIORE, M.; MELO, V.A. (Org.). História do Esporte no Brasil: do império aos dias atuais. São Paulo: Editora UNESP, p.35-70, 2009b.

MORGADO, F. Adestramento do cavalo. São Paulo: Nobel, 1990.

NOVOS rumos tomará o hipismo nacional. Hipismo. Equi. Rio de Janeiro, 1938, p. 2024.

PEREIRA, E.L. As práticas equestres em Porto Alegre: percorrendo o processo da esportivização. 2012. 156 f. Dissertação (Mestrado) -- Universidade Federal do Rio Grande do Sul, Escola de Educação Física, Programa de Pós-Graduação em Ciências do Movimento Humano, Porto Alegre, 2012. Disponível em: $<$ http://www.bibliotecadigital.ufrgs.br/da.php? $\mathrm{nrb}=000861427 \& \mathrm{loc}=2012 \& \mathrm{l}=\mathrm{d} 78 \mathrm{f3c} 8 \mathrm{f} 7$ d03f59a >. Acesso em: 25 nov. 2013.

PEREIRA, E.L.; LYRA, V.B.; MAZO, J.Z. Corridas de cavalo em cancha reta em Porto Alegre (1852/1877): uma prática cultural-esportiva sul-rio-grandense. Revista da Educação Física/UEM. Maringá, v.21, n.4, 2010. Disponível em: $<$ http://periodicos.uem.br/ojs/index.php/RevEducFis/article/viewFile/8164/6770>.

Acesso em: 06 mai. 2011.

O turfe em Porto Alegre/Rio Grande do Sul: aspectos históricos de uma prática

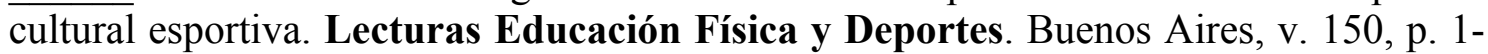
15, 2010. Disponível em: http://www.efdeportes.com/efd150/o-turfe-aspectoshistoricos-de-uma-pratica-esportiva.htm. Acesso em: 17 jan. 2011.

PIMENTEL, A. O método da análise documental: seu uso numa pesquisa historiográfica. Cadernos de Pesquisa. São Paulo, n. 114, p. 179-195, novembro/2001. Disponível em: < http://www.scielo.br/pdf/cp/n114/a08n114.pdf $>$. Acesso em: 13 jun. 2011.

Quarta RPMON, da Brigada Militar, comemora 93 anos. PM5-Imprensa/BM. 22/01/2009. Disponível em: $<$ http:www.ssp.rs.gov.br/portal/principal.php?action=imp_noticias\&cod_noticia $=12498$ >. Acesso em: 27 mai. 2014.

RIBEIRO, A. C. Os bastidores de um hipódromo. Revista do Globo. 26/07/1944, n. 366. Porto Alegre: FEFID/PUCRS;ESEF/UFRGS, 2004, CD-ROM. 
RINK, B. Desvendando o enigma do centauro: como a união homem-cavalo acelerou a história e transformou o mundo. - São Paulo: Equus Brasil, 2008.

RODRIGUES, M. Constituição e enraizamento do esporte na cidade: Uma prática moderna de lazer na cultura urbana de Belo Horizonte (1894-1920). 2006. Belo Horizonte. UFMG/Faculdade de Filosofia e Ciências Humanas (Tese de doutorado). Disponível em: http://www.bibliotecadigital.ufmg.br/dspace/bitstream/1843/VCSA6XTGT2/1/tese marilita vers o final.pdf. Acesso em: 24 nov. 2009.

ROESSLER, M.; RINK, B. Esportes Hípicos. In: DA COSTA, L. (Org.). Atlas do Esporte no Brasil. Rio de Janeiro: CONFEF, 2006, p.8216-8219. Disponível em: < http://www.atlasesportebrasil.org.br/textos/51.pdf>. Acesso em: 27 mai.2014.

ROZAnO, M.; FOnSECA, R. (Org.). História de Porto Alegre: Jockey Club. Porto Alegre: Nova Prova, 2005.

RUBERT, A. História da Igreja no Rio Grande do Sul. Porto Alegre: EDIPUCRS, 1998.

A SEMANA do cavallo de guerra. 16/01/1932, n. 78, p. 33. In: MAZO, J.Z. O Esporte e a Educação Física na Revista do Globo: Catálogo 1929-1967. Porto Alegre: FEFID/PUCRS; ESEF/UFRGS, 2004, CD-ROM.

7 DE SETEMBRO. Semanário Turfista. Porto Alegre, 1930, p.2.

STÉDILE, M. E. Da fábrica à várzea: clubes de futebol operário em Porto Alegre (1931-1937). EFDeportes.com, Revista Digital. Buenos Aires, ano 15, $\mathrm{n}^{\circ} 151$, dezembro de 2010. Disponível em: < http://www.efdeportes.com/efd151/da-fabrica-avarzea-clubes-de-futebol-operario.htm>. Acesso em: 5 dez. 2011.

TALHA, J. Moinhos de Vento: o Epson de Porto Alegre. 22/07/1939. n.256, p.36. In: MAZO, J.Z. O Esporte e a Educação Física na Revista do Globo: Catálogo 19291967. Porto Alegre: FEFID/PUCRS; ESEF/UFRGS, 2004, CD-ROM.

TURF. 08/07/1939, n. 255, p.36. In: MAZO, J.Z. O Esporte e a Educação Física na Revista do Globo: Catálogo 1929-1967. Porto Alegre: FEFID/PUCRS; ESEF/UFRGS, 2004, CD-ROM.

VEM CORRER o "G.P. Bento Gonçalves": o derrubador de records. Supplemento. Porto Alegre, 20/09/1939, p.11.

VIEIRA, S.; FREITAS, A. O que é hipismo. Rio de Janeiro: Casa da Palavra: COB, 2007.

\section{Endereço das Autoras:}

Ester Liberato Pereira

Av. Bento Gonçalves, 2306/701 - Bairro Partenon

Porto Alegre - RS - 90650-001 
Endereço Eletrônico: ester_lp@yahoo.com.br

Janice Zarpellon Mazo

Av. cel. Lucas de Oliveira, 2507/402 Bairro Petrópolis

Porto Alegre - RS - 90460-001

Endereço Eletrônico: janmazo@terra.com.br 